\title{
The Structure and Abundance of Cartilage Proteoglycans during Early Development of the Human Fetus
}

\author{
PETER J. ROUGHLEY, ROBERT J. WHITE, AND TIBOR T. GLANT \\ Joint Diseases Laboratory, Shriners Hospital for Crippled Children, Montreal, Quebec, Canada and Institute of \\ Anatomy, Histology and Embryology, University of Medicine, Debrecen, Hungary [T.T.G.]
}

\begin{abstract}
Proteoglycan was isolated from the epiphyseal cartilage of the knee joint from human fetuses, ranging in age from 11 to 19 wk of gestation. The content of proteoglycan, per wet weight of cartilage, increased with gestational age, and structural changes were observed in the proteoglycan subunits, particularly with respect to hydrodynamic size and the position of sulfation of the chondroitin sulfate chains. While 6-sulfation remained fairly constant on about half the disaccharide residues during the age period examined, the proportion of nonsulfated residues decreased with gestational age and there was a corresponding increase in the proportion of 4-sulfated residues. Other structural parameters showed little change, and after 11 wk of gestation the majority of proteoglycan subunits were able to interact with hyaluronic acid to form aggregates. Link proteins were detected in the cartilage at all ages and their abundance increased with age relative to other cartilage proteins. They showed little change in structural heterogeneity, with the two larger molecular forms predominating. In contrast to the proteoglycans, cartilage proteins were in high abundance at 11 wk of gestation, but decreased considerably with time, although there was little change in the relative proportion of the majority of the components. (Pediatr Res 22: 409413, 1987)
\end{abstract}

Abbreviation

SDS, sodium dodecyl sulfate

Hyaline cartilage is best depicted as a solution of proteoglycan and matrix proteins entrapped within a network of collagen fibrils containing a sparse population of cells. The composition of the extracellular matrix is not constant throughout life, and this is particularly true for the proteoglycan, whose structure shows considerable variation. In the human the major changes after birth take place in the first two decades of life (1), representing the period of skeletal development. They are typified by a decrease in the size of the proteoglycan subunit, a decrease in both the size and number of chondroitin sulfate chains, and an increase in the size and number of keratan sulfate chains $(2,3)$. This latter change occurs concomitantly with a decrease in the number of $O$-linked oligosaccharides $(4,5)$. Such changes in

Received February 24, 1987; accepted May 7, 1987.

Correspondence Dr. P. J. Roughley, Joint Diseases Laboratory, Shriners Hospital for Crippled Children, 1529 Cedar Avenue, Montreal, Quebec H3G 1A6, Canada.

Supported by the Medical Research Council of Canada and the Shriners of North America. glycosylation probably reflect a change in the synthetic capacity of the chondrocytes.

The core protein of the proteoglycan subunits also shows structural changes over the same age period. These are reflected in the variation in amino acid composition, although it is still open to question whether the changes reflect the synthesis of unique core proteins or degradation of a common precursor (68 ). Irrespective of their origin, the majority of proteoglycan subunits at all ages possesses the ability to interact with hyaluronic acid. Changes due to proteolytic degradation are more definitive in the link proteins, and appear to progress continuously throughout life (9).

Such changes in proteoglycan structure are not unique to the human, but have also been shown in a variety of animals (1016). Again, the changes in glycosylation appear to be predominant between birth and the end of growth (17). While the type of changes appears common to all the mammals, the magnitude of the change is variable between the species. Changes during the prenatal period have also been described in bovine cartilage (1821). From first trimester to birth the size of both the proteoglycan subunits and the chondroitin sulfate chains decreases. There was, however, no change in the sulfation position along the chondroitin sulfate chains, which shows considerable variation after birth. Similarly, the amino acid composition of the core proteins showed little change during the prenatal period. In the human, little information is available for the prenatal period, particularly from mid-first trimester, when the cartilagenous rudiments become evident in the developing limb, to late second trimester. During this period major changes are occurring in the cartilagenous anlage of the long bones, with respect to growth and the development of the osseous diaphysis (22).

It is also well accepted that genetic abnormalities in the cartilage matrix macromolecules can lead to skeletal dysplasias that are often evident in the fetus. Some such changes are known to affect the proteoglycan subunits. In animals, changes in the expression of the core protein $(23,24)$ or in the structure of the chondroitin sulfate chains $(25,26)$ have been shown to produce a disproportionate dwarfism. In the human, such abnormalities are less well characterized, although defects involving proteoglycan have been postulated (27-30). Many such genetic abnormalities may be lethal to the fetus and result in premature delivery of a stillborn or a therapeutic abortion. In either case, if one is to study the biochemical origin of the defect it is essential to have normal control tissue of similar gestational age, to eliminate the possibility that structural changes may merely reflect normal embryonic and fetal development rather than be the result of a disease state. The purpose of this work, therefore, was to determine the changes in cartilage proteoglycan structure that may accompany the early developmental stages in the human fetus. 


\section{METHODS}

Materials. Cesium chloride was from Accurate Chemical \& Scientific Corp.; hyaluronic acid, guanidine hydrochloride, ethylenediaminetetraacetic acid, pepstatin, phenylmethylsulfonyl fluoride, iodoacetamide, and agarose were from Sigma Chemical Co.; chondroitinase ABC was from Miles Laboratories Inc.; sodium dodecyl sulfate, acrylamide, methylenebisacrylamide, Coomassie Brilliant Blue and nitrocellulose sheets were from Bio-Rad Laboratories; Sepharose CL-2B was from Pharmacia Fine Chemicals; and Zysorbin was from Dimension Laboratory.

Preparation of proteoglycan. Cartilage was obtained from the proximal tibial and distal femoral epiphyses of human fetuses obtained from individuals undergoing therapeutic abortions. Gestational age was assessed from measurement of femoral length (31), and tissue was pooled into five groups according to gestational age. The following average age groups were used: 1) 11 wk representing eight specimens of 6-7 mm, 2) $13 \mathrm{wk}$ representing three samples of $11-12 \mathrm{~mm}, 3) 14.5 \mathrm{wk}$ representing two samples of $15-16 \mathrm{~mm}$, 4) 16 wk representing two samples of 19-20 mm, and 5) $19 \mathrm{wk}$ representing one sample of $30 \mathrm{~mm}$. Each group represented about $1 \mathrm{~g}$ cartilage. The tissue was divided into small pieces (about $1 \mathrm{~mm}^{3}$ ) and extracted with $4 \mathrm{M}$ guanidinium chloride containing proteinase inhibitors, as described previously (1). The extract was subjected directly to cesium chloride density gradient centrifugation under dissociative conditions, and proteoglycan subunits and cartilage proteins were recovered from fractions having a density greater than 1.52 $\mathrm{g} / \mathrm{ml}$ (D1 preparation) or less than $1.45 \mathrm{~g} / \mathrm{ml}$ (D3 preparation) respectively.

Analysis of proteoglycan. Uronic acid content was determined by the carbazole assay (32) and sialic acid by the periodateresorcinol method (33). Hexosamines and amino acids were determined on a Durrum amino acid analyzer after hydrolysis of samples. Hydrolysis was performed in $4 \mathrm{M} \mathrm{HCl}$ for $8 \mathrm{~h}$ at $100^{\circ}$ $\mathrm{C}$ for hexosamine analysis and in $6 \mathrm{M} \mathrm{HCl}$ for $20 \mathrm{~h}$ at $105^{\circ} \mathrm{C}$ under a nitrogen atmosphere for amino acid analysis. Protein content was estimated by summation of the amino acids, without correction for losses during the hydrolysis procedure. The position of sulfation of the chondroitin sulfate chains was determined by high-performance liquid chromatography (34) of the unsaturated disaccharides produced by the action of chondroitinase ABC (35). The chromatography system utilized a LiChrosorb$\mathrm{NH}_{2}$ column (36) and an acetate buffer system (37). Proteoglycan size was estimated by chromatography through Sepharose CL2B as previously described (38), and the ability to aggregate was assessed by adding $2 \%$ hyaluronic acid $(w / w)$ to the sample prior to chromatography.

Electrophoresis. Proteoglycan was analyzed in agarose/polyacrylamide composite gels (39). After electrophoresis gels were stained with toluidine blue as described previously (1). Cartilage proteins were analyzed in $10 \%$ polyacrylamide gels by the method of King and Laemmli (40), and stained with Coomassie Brilliant Blue by the method of Fairbanks et al. (41). Alternatively, protein was transferred from the gel to nitrocellulose by the method of Towbin et al. (42), and link proteins were specifically visualized by direct immune staining with a monoclonal antibody (9/30/8-A-4), labeled with ${ }^{125}$ I by the method of Greenwood et al. (43), and subsequent autoradiography (44).

Radioimmunoassay. Monoclonal antibodies were used in competitive assays to detect the presence of fetal and adult type core proteins. Antibody $\alpha \mathrm{HFPG}-846$ recognizes epitopes on proteoglycans from fetal cartilage, and EGF-4 recognizes epitopes on adult proteoglycans $(8,45)$. Optimal dilutions of monoclonal antibodies (1/15,000 for EFG -4 and $1 / 400$ for $\alpha$ HFPG-846) were incubated with serial dilutions of unlabeled proteoglycans overnight at $37^{\circ} \mathrm{C}$, and then with ${ }^{125}$ I-labeled fetal $(23-27$ wk gestation) or adult (52-56 yr) cartilage proteoglycans. Immune complexes formed with EGF-4 (IgG1) were precipitated by protein-A bearing Staphylococcus aureus (Zysorbin). Immune com- plexes formed with $\alpha$ HFPG-846 (IgM) were complexed with rabbit anti-mouse IgM and this tertiary complex was then precipitated with Zysorbin. Percentage inhibition was calculated from the ratio of ${ }^{125} \mathrm{I}$-material precipitated in the presence of unlabeled antigen to that precipitated in its absence.

\section{RESULTS}

Proteoglycan subunits were isolated from the epiphyseal cartilage of the knee joint from human fetuses ranging in gestational age from 11 to $19 \mathrm{wk}$. During this time period the yield of the proteoglycan (D1 preparation) increased from 11.4 to $29.9 \mathrm{mg} /$ $\mathrm{g}$ wet weight of tissue, upon extraction with $4 \mathrm{M}$ guanidinium chloride (Table 1). This preparation included the bulk of the uronic acid-containing material in all cases. Analysis of the purified proteoglycan preparations showed increases in the proportion of uronic acid, sialic acid, glucosamine, galactosamine, and protein when measured per dry weight basis, indicating a change in the composition of the preparations. However, when results are expressed relative to the weight of protein the changes are less apparent, suggesting that the degree of glycosylation of the proteoglycan subunits may be similar at all ages.

Some structural changes are, however, apparent. The ratio of galactosamine to glucosamine increased with gestational age, while that of glucosamine to sialic acid decreased (Table 1). As this latter ratio is always less than 2 , there is little evidence for the presence of keratan sulfate of any significant chain length at any age, and the decrease in the ratio suggests that any keratan sulfate is not increasing in abundance with fetal age. While the galactosamine values indicate that chondroitin sulfate is predominant at all ages, the structure of the chains does change markedly with age. At all ages studied, 6-sulfation accounted for about $55 \%$ of the disaccharides forming the chondroitin sulfate. With the remaining disaccharides, nonsulfated residues predominated at early points and 4-sulfated residues at later times (Fig. 1). The overall trend then is an increase in the sulfation of the chondroitin sulfate with gestational age, apparently due to the substitution of nonsulfated galactosamine residues with sulfate at their 4position.

The core protein of the proteoglycans showed only minimal variation in composition with gestational age (Table 2). In general there were no consistent trends to prove that multiple core proteins are present, suggesting that any changes in glycosylation may be occurring on a common core protein. Some support for this conclusion was obtained by radioimmunoassay (Table 3). The immunological reactivity of the various preparations was similar toward a monoclonal antibody ( $\alpha \mathrm{HFPG}-846)$ that recognizes a protein-related epitope on fetal human cartilage proteoglycans, and in no case was cross-reactivity observed toward

Table 1. Yield and composition of proteoglycan preparations

\begin{tabular}{lrrrrr}
\hline & \multicolumn{5}{c}{ Gestational age (wk) } \\
\cline { 2 - 6 } & \multicolumn{1}{c}{11} & \multicolumn{1}{c}{13} & 14.5 & \multicolumn{1}{c}{16} & \multicolumn{1}{c}{19} \\
\hline D1* (mg/g wet cartilage) & 11.4 & 11.5 & 16.8 & 24.2 & 29.9 \\
D3 $\dagger$ & 33.3 & 19.5 & 11.2 & 7.9 & 5.9 \\
GlcUA $\ddagger(\mathrm{mg} / 100 \mathrm{mg}$ & 18.4 & 20.8 & 22.6 & 23.9 & 22.8 \\
D1) & & & & & \\
NeuAc & 1.0 & 1.4 & 1.5 & 1.6 & 1.8 \\
GlcNAc & 1.4 & 1.6 & 1.7 & 1.7 & 1.7 \\
GalNAc & 15.0 & 20.2 & 23.5 & 21.7 & 24.3 \\
Protein & 4.6 & 5.4 & 5.8 & 6.1 & 6.6 \\
GalN:GlcN (molar ra- & 10.7 & 12.6 & 13.8 & 12.8 & 14.3 \\
tio) & & & & & \\
GlcNAc: NeuAc & 2.0 & 1.6 & 1.6 & 1.5 & 1.3 \\
\hline
\end{tabular}

*D1, proteoglycan subunit preparation with density greater than 1.52 $\mathrm{g} / \mathrm{ml}$.

$\dagger \mathrm{D} 3$, cartilage protein preparation with density less than $1.45 \mathrm{~g} / \mathrm{ml}$.

$\ddagger$ GlcUA, glucuronic acid; NeuAc, N-acetyl neuraminic acid (sialic acid); GlcNAc, N-acetyl glucosamine; GalNAc, N-acetyl galactosamine. 


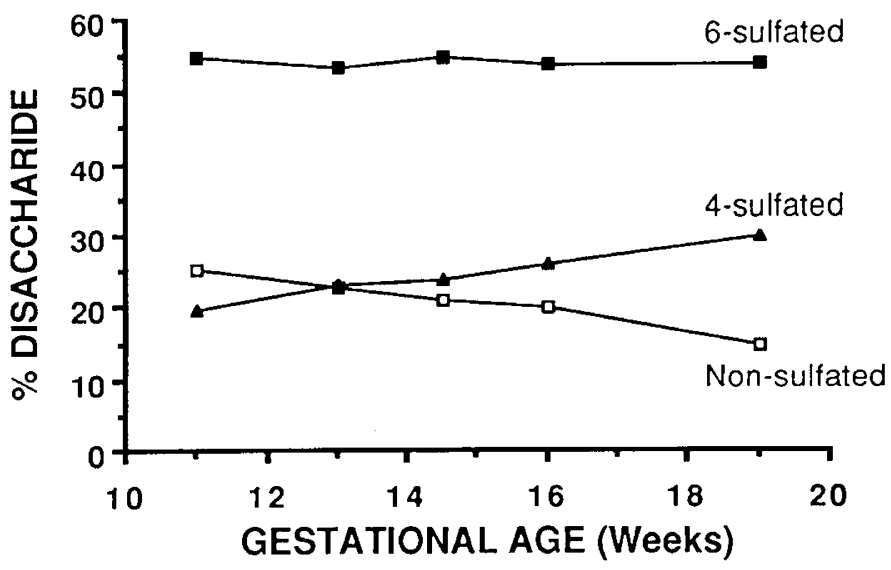

Fig. 1. Sulfation position of chondroitin sulfate in proteoglycan subunit preparations. Disaccharides were prepared by the action of chondroitinase $\mathrm{ABC}$, then quantitated by high-performance liquid chromatography. The molar percentages of 6-sulfated $(\boldsymbol{\square} \mathbf{\square})$, 4-sulfated $(\boldsymbol{\Lambda}-\boldsymbol{\Lambda})$, and nonsulfated $(\square-\square)$ disaccharides are indicated for the various gestational ages.

Table 2. Amino acid analysis of proteoglycan preparations

\begin{tabular}{lrrrrr}
\hline & \multicolumn{4}{c}{ Gestational age (wk) } \\
\cline { 2 - 6 } & 11 & 13 & 14.5 & 16 & 19 \\
\hline Asp (residues/1000 residues) & 77 & 74 & 70 & 71 & 72 \\
Thr & 71 & 72 & 74 & 75 & 74 \\
Ser & 117 & 120 & 115 & 109 & 113 \\
Glu & 148 & 146 & 148 & 144 & 147 \\
Pro & 79 & 84 & 87 & 91 & 89 \\
Gly & 135 & 134 & 130 & 128 & 127 \\
Ala & 77 & 76 & 75 & 77 & 78 \\
Val & 58 & 61 & 62 & 64 & 63 \\
Met & 2 & 2 & 2 & 2 & 2 \\
Ile & 46 & 46 & 49 & 50 & 47 \\
Leu & 77 & 78 & 81 & 84 & 83 \\
Tyr & 17 & 16 & 17 & 18 & 17 \\
Phe & 29 & 28 & 28 & 29 & 29 \\
His & 16 & 16 & 15 & 14 & 14 \\
Lys & 22 & 20 & 17 & 16 & 17 \\
Arg & 29 & 27 & 30 & 29 & 30 \\
\hline
\end{tabular}

an antibody (EFG-4) that recognizes only the core protein of proteoglycans from adult cartilage $(8,45)$. In all cases inhibition curves of the various proteoglycan preparations toward $\alpha$ HFPG846 were parallel, and with the exception of the preparation from the youngest individuals the amount of material required to give $50 \%$ inhibition was similar. Further evidence for the structural similarity between the different proteoglycan preparations was shown by their similar mobilities on agarose/polyacrylamide gel electrophoresis. In all cases only one major component was observed (Table 3), as is characteristic of third trimester and neonatal cartilage preparations (1).

The hydrodynamic size of the proteoglycan subunits showed some changes over the age range studied (Fig. 2). The average size of the molecules were larger at $14.5 \mathrm{wk}$ than at either 11 or $19 \mathrm{wk}$, although the difference was not great, with $\mathrm{K}_{\mathrm{av}}$ values varying from 0.15 to 0.18 (Table 3). In addition, the material from the youngest gestational age appears to show two populations of uronic acid-containing material, with only the larger major population interacting with hyaluronic acid. The older preparations showed only single populations, which interact well with hyaluronic acid (Fig. 2). The percentage aggregation, measured as the amount of uronic acid-containing material eluting at the void volume on Sepharose CL-2B when chromatography was performed in the presence of hyaluronic acid, was $48 \%$ at $11 \mathrm{wk}$ gestation and between 70 to $75 \%$ at the older ages (Table 3 ).
Table 3. Physical properties of proteoglycan preparations

\begin{tabular}{lccccc}
\hline & \multicolumn{5}{c}{ Gestational age (wk) } \\
\cline { 2 - 6 } & 11 & 13 & 14.5 & 16 & 19 \\
\hline $\mathrm{K}_{\mathrm{av}}{ }^{*}$ & 0.18 & & 0.15 & & 0.18 \\
$\%$ aggregation $\dagger$ & 48 & & 74 & & 71 \\
$\mathrm{R}_{\mathbf{x}} \neq$ & 0.70 & 0.70 & 0.68 & 0.68 & 0.70 \\
$\mathrm{I}_{50}: \alpha \mathrm{HFPG}-846(\mathrm{ng}) \S$ & 210 & 120 & 170 & 150 & 170 \\
$\mathrm{I}_{50}:$ EFG-4 & $\mathrm{NII}$ & $\mathrm{NI}$ & $\mathrm{NI}$ & $\mathrm{NI}$ & $\mathrm{NI}$ \\
\hline
\end{tabular}

* Partition coefficient derived by chromatography through Sepharose CL-2B.

$\dagger$ Proportion of uronic acid eluting at the void volume after chromatography through Sepharose CL-2B in the presence of hyaluronic acid.

$\ddagger$ Electrophoretic mobility relative to bromophenol blue after electrophoresis on agarose/polyacrylamide gels.

$\S$ Amount of proteoglycan required to produce $50 \%$ inhibition in a radioimmunoassay using the monoclonal antibody indicated ( $\alpha$ HFPG846 or EFG-4).

\| Not inhibited with up to 1600 ng proteoglycan, whereas $50 \%$ inhibition is produced by $60 \mathrm{ng}$ adult proteoglycan.

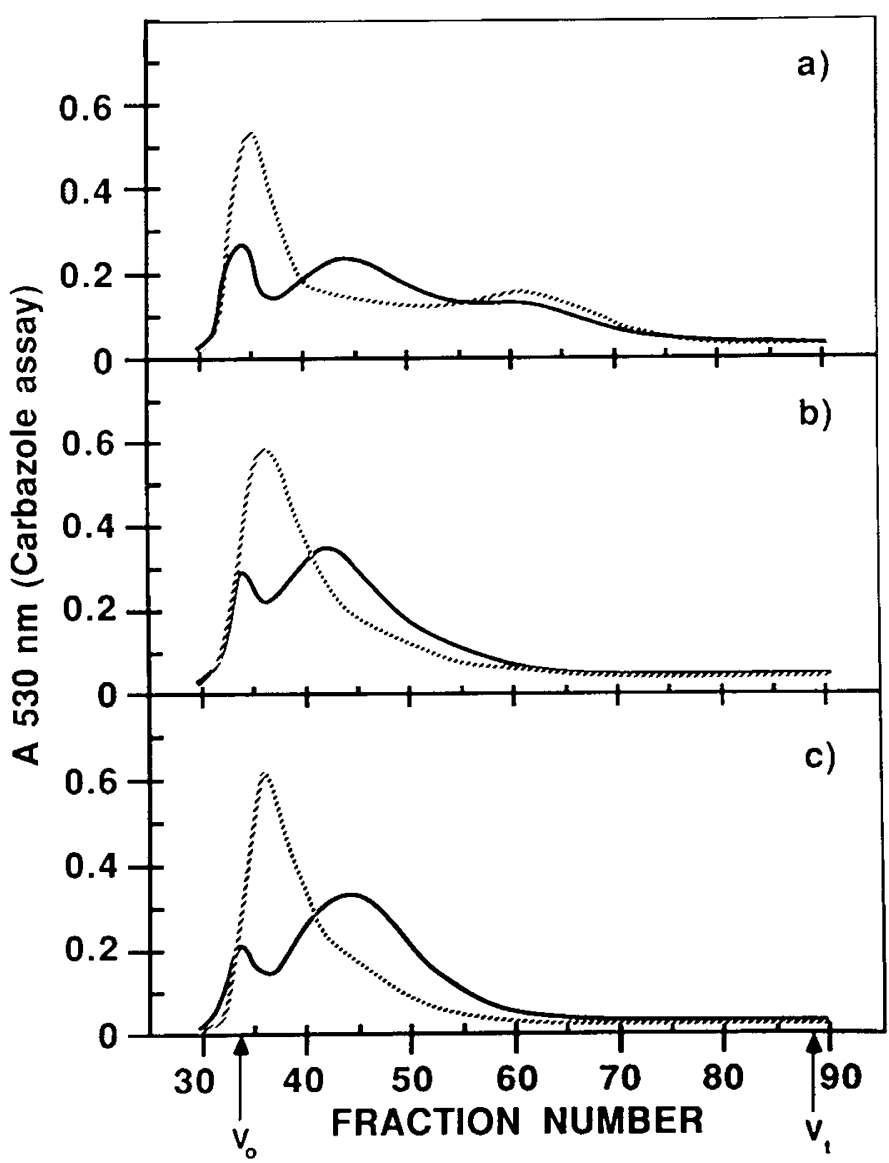

Fig. 2. Sepharose CL-2B chromatography of proteoglycan subunit preparations. Samples were prepared from fetal cartilage of gestational age $a) 11 \mathrm{wk}, b) 14.5 \mathrm{wk}$, and $c$ ) $19 \mathrm{wk}$. Column effluents were monitored for uronic acid content by the carbazole assay (A530 nm). Chromatography was performed in the absence (-) or presence (---) of $2 \%$ $\mathrm{w} / \mathrm{w}$ hyaluronic acid. The column void volume $\left(\mathrm{V}_{\mathrm{o}}, 34 \mathrm{ml}\right)$ and total volume $\left(\mathrm{V}_{\mathrm{t}}, 88 \mathrm{ml}\right)$ are indicated.

When the cartilage proteins (D3 preparations) were examined by SDS/polyacrylamide gel electrophoresis, link proteins were found to be present at all ages. They were of similar mobility to their counterparts present in newborn cartilage, although the two larger components predominated (Fig. 3). As a proportion of the cartilage protein preparation, the abundance of the link proteins 


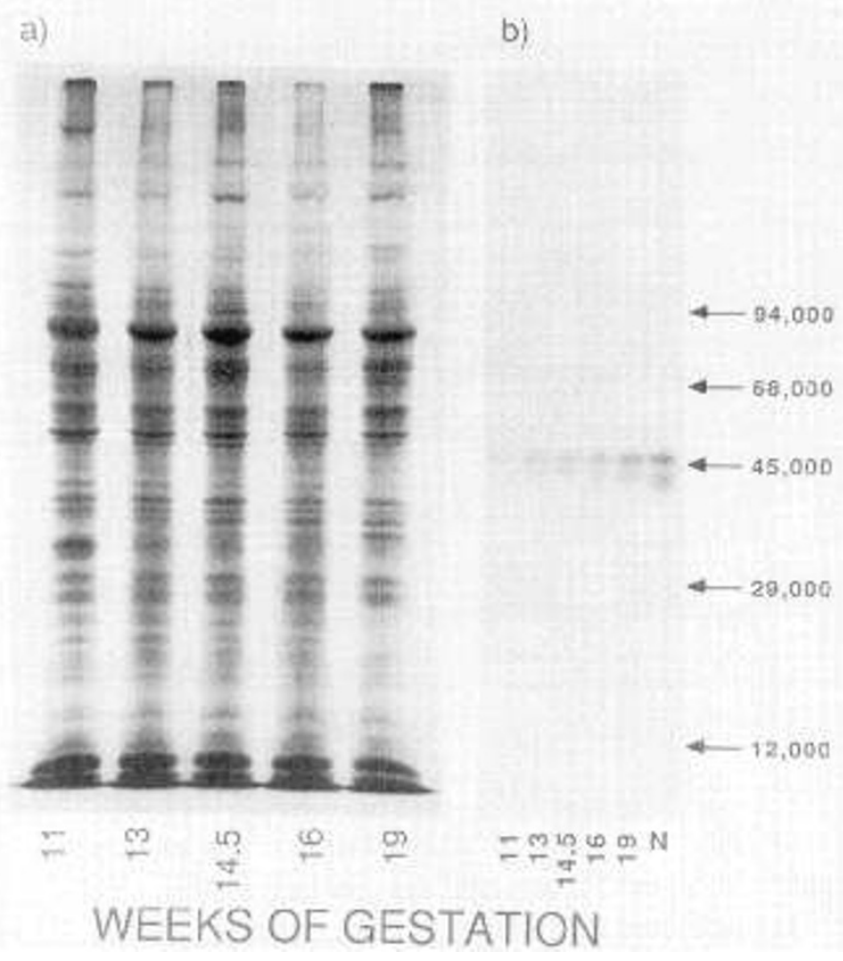

Fig. 3. SDS/polyacrylamide gel electrophoresis of cartilage protein preparations. Electrophoresis was performed under reducing conditions in $10 \%$ polyacrylamide gels. Proteins in the gel were $a$, stained directly with Coomassie Brilliant Blue or $b$, electroblotted onto nitrocellulose and link proteins specifically identified by incubation with an iodinated monoclonal antibody (9/30/8-A-4) and subsequent autoradiography. Samples are from fetuses of gestational ages 11, 13, 14.5, 16, and $19 \mathrm{wk}$ and a newborn $(N)$.

increased with gestational age. However, this need not necessarily reflect a change in the total tissue content of link protein, as the cartilage protein preparation yields decreased considerably from 11 to 19 wk gestation (Table 1), as previously described in bovine cartilage (19). At the youngest gestational age the protein accounted for about three times the weight of the proteoglycan, whereas at 19 wk it was only about one-fifth the weight of the proteoglycan. Analysis of the SDS/polyacrylamide gel by Coomassie Brilliant Blue staining showed little difference in relative distribution for the majority of constituent proteins over this age period (Fig. 3), although some proteins, for example those having molecular weights between 30,000 and 40,000 , do show distinct age-related trends.

\section{DISCUSSION}

The results show that over the period of human fetal development from late first trimester (11 wk) to mid-second trimester (19 wk) changes are occurring in the composition of the cartilage matrix, particularly with respect to the increase in abundance of proteoglycan and the decrease in abundance of cartilage proteins. With further development the proteoglycan and protein content would be expected to increase until birth, with the extractable proteoglycan subunits doubling in concentration from $19 \mathrm{wk}$ gestation to term, when they represent about $60 \mathrm{mg} / \mathrm{g}$ wet cartilage in the knee (1). After birth the concentration of such high-density proteoglycan subunits drops continuously with age to reach about $20 \mathrm{mg} / \mathrm{g}$ in the mature adult.

With respect to the proteoglycan subunits themselves there are considerable similarities in some structural parameters, such as the composition of the core protein and the electrophoretic mobility of the molecules. Furthermore, there is little change occurring to these parameters between early third trimester and birth (1), suggesting that during the whole fetal period, the proteoglycan subunits may exist on a single common core protein. A similar situation was also reported in the bovine fetus (18). After birth multiple proteoglycan populations are evident and the structure of the core protein changes considerably. These changes are due partly to variation in the glycosylation pattern of the molecules, particularly in the abundance of chondroitin sulfate and keratan sulfate, and partly to proteolytic modification of the initially produced core protein. The production of genetically distinct core proteins during the period of postnatal development has also been suggested (8).

The carbohydrate composition of the fetal proteoglycans shows some variations, although at all gestational ages there appears to be a similar content of chondroitin sulfate and little keratan sulfate. This sparsity in keratan sulfate in the human fetus is in contrast to the bovine fetus, where keratan sulfate has been identified throughout fetal development (21). In the human, the abundance of chondroitin sulfate and keratan sulfate does not appear to change prior to birth, after which chondroitin sulfate content decreases and keratan sulfate content increases (1). There is, however, considerable variation in the degree and position of sulfation of the chondroitin sulfate chains during the fetal period, with the chains at early periods bearing $25 \%$ nonsulfated disaccharides. The degree of sulfation increases to $85 \%$ by $19 \mathrm{wk}$ and $90-95 \%$ by birth. During this time the amount of 6 -sulfation remains fairly constant but 4-sulfation increases, until by birth it is approaching the level of 6-sulfation. After birth there is little change in the degree of sulfation but 4-sulfation declines continuously to reach about $5 \%$ in the adult as 6 -sulfation predominates. In the bovine system there is little change in the position of sulfation of chondroitin sulfate isolated from the femoral condyles during fetal development, but the size of the chains decreases (18). Differences in structural changes during fetal development between the bovine and the human are not surprising in view of the fact that by birth the bovine long bones have epiphyses containing well-developed subchondral bone with articular cartilage on the surface, whereas in the human the secondary centers of ossification are only just developing in the epiphyses and therefore the articular cartilage is still indistinguishable from the bulk of the epiphyseal cartilage.

Link proteins are present at all stages of fetal cartilage development, and as with the newborn three components of molecular weights $48,000,44,000$, and 41,000 are present (46), although the smallest component, which is thought to be a proteolytic derivative of the larger (47), is much less abundant. This component increases in concentration during postnatal life (9) together with the production of further fragmented link proteins held in a pseudo-native conformation by disulfide bonds. Such fragmentation was not evident at any stage of fetal development, even though major changes in matrix organization are presumably taking place during this period of rapid growth and development.

It thus appears that structurally the aggregating proteoglycans change little during fetal development, except in their sulfation pattern and possibly their hydrodynamic size. The variation in proteoglycan size is most apparent at the earliest gestational age and may reflect a multiplicity of cell types persisting in the cartilagenous rudiment that has only recently developed from the mesenchyme. Such cellular heterogeneity would be expected to decrease rapidly with fetal development. Such an explanation might also account for other differences between the youngest preparation and its more mature counterparts. The reason for the change in sulfation pattern of the chondroitin sulfate chains remains to be established, as it is not clear whether this could be of any functional significance on the water binding properties of the proteoglycan or its interaction with other matrix components. The other major change, relating to increase in proteoglycan content, is perhaps more expected as the developing cartilage assumes an organization compatible with its functional role after 
birth, that, at least in the articulating cartilages, requires the water binding and osmotic properties associated with high proteoglycan concentrations (48). It may be significant that the two best described genetic defects relating to proteoglycan structure affect 1) the expression of the core protein, resulting in depleted proteoglycan levels (24), and 2) the sulfation of the chondroitin sulfate chains (25), indicating the importance of these parameters for normal development.

Acknowledgments. The authors thank Ms. Michele BurmanTurner for typing the manuscript and Mr. Mark Lepic for preparing the figures. We are also indebted to Dr. Y. Lefebvre, Chairman, Department of Obstetrics and Gynecology, University of Montreal, and the staff at Hopital Notre-Dame for provision of cartilage specimens, and to Dr. Bruce Caterson, Department of Biochemistry, University of West Virginia, for providing the monoclonal antibody (9/30/8-A-4) against link protein.

\section{REFERENCES}

1. Roughley PJ, White RJ 1980 Age-related changes in the structure of the proteoglycan subunits from human articular cartilage. J Biol Chem 255:217114

2. Bayliss MT, Ali SY 1978 Age-related changes in the composition and structure of human articular cartilage proteoglycans. Biochem J 176:683-694

3. Elliot RJ, Gardner DL 1979 Changes with age in the glycosaminoglycans of human articular cartilage. Ann Rheum Dis 38:371-377

4. Roughley PJ, White RJ, Santer V 1981 Comparison of proteoglycans extracted from high and low weight-bearing human articular cartilage, with particular reference to sialic acid content. J Biol Chem 256:12699-12704

5. Santer V, White RJ, Roughley PJ 1982 O-linked oligosaccharides of human articular cartilage proteoglycans. Biochim Biophys Acta 716:277-282

6. Triphaus GF, Schmidt A, Buddecke E 1980 Age-related changes in the incorporation of $\left.{ }^{35} \mathrm{~S}\right]$-sulfate into two proteoglycan populations from human cartilage. Hoppe-Seylers Z Physiol Chem 361:1773-1779

7. Champion BR, Reiner A, Roughley PJ, Poole AR 1982 Age-related changes in the antigenicity of human articular cartilage proteoglycans. Collagen Relat Res 2:45-60

8. Glant TT, Mikecz K, Roughley PJ, Buzas E, Poole AR 1986 Age-related changes in protein-related epitopes of human articular cartilage proteoglycans. Biochem J 236:71-75

9. Mort JS, Poole AR, Roughley PJ 1983 Age-related changes in the structure of proteoglycan link proteins present in normal human articular cartilage. Biochem J 214:269-272

10. Simůnek Z, Muir H 1972 Changes in protein-polysaccharides of pig articular cartilage during prenatal life, development and old age. Biochem J 126:515523

11. Inerot S, Heinegård D, Audell L, Olsson SE 1978 Articular cartilage proteoglycans in ageing and osteoarthritis. Biochem J 169:143-156

12. Sweet MBE, Thonar EJMA, Marsh J 1979 Age-related changes in proteoglycan structure. Arch Biochem Biophys 198:439-448

13. Murata K, Bjelle AO 1980 Constitutional variations of acidic glycosaminoglycans in normal and arthritic bovine articular cartilage proteoglycans at different ages. Connect Tissue Res 7:143-156

14. Garg HG, Swann DA 1981 Age-related changes in the chemical composition of bovine articular cartilage. The structure of high-density proteoglycans. Biochem J 193:459-468

15. Theocharis DA, Tsiganos CP 1985 Age-related changes of proteoglycan subunits from sheep nasal cartilage. Int J Biochem 17:479-484

16. Theocharis DA, Kalpaxis DL, Tsiganos CP 1985 Cartilage keratan sulphate: changes in chain length with ageing. Biochim Biophys Acta 841:131-134

17. Inerot S, Heinegård D 1983 Bovine tracheal cartilage proteoglycans. Variations in structure and composition with age. Collagen Relat Res 3:245-262

18. Thonar EJMA, Sweet MBE 1981 Maturation-related changes in proteoglycans of fetal articular cartilage. Arch Biochem Biophys 208:535-547

19. Pal S, Tang LH, Choi H, Haberman E, Rosenberg L, Roughley PJ, Poole AR 1981 Structural changes during development in bovine fetal epiphyseal cartilage. Collagen Relat Res 1:151-176

20. Buckwalter JA Rosenberg L 1983 Structural changes during development in bovine fetal epiphyseal cartilage. Collagen Relat Res 3:489-504
21. Thonar EJMA, Björnsson S, Kuettner KE 1986 Age-related changes in cartilage proteoglycans. In: Kuettner KE, Schleyerbach R, Hascall VC (eds) Articular Cartilage Biochemistry. Raven Press, New York, pp 273-288

22. Crelin ES 1981 Development of the musculoskeletal system. In: Clinical Symposia, Vol. 33, No. 1. Ciba Pharmaceutical Company, Summit, NJ

23. Pennypacker JP, Goetinck PF 1976 Biochemical and ultrastructural studies of collagen and proteochondroitin sulfate in normal and nanomelic cartilage. Dev Biol 50:35-47

24. Kimata K, Barrach HJ, Brown KS, Pennypacker JP 1981 Absence of proteoglycan core protein in cartilage from the $\mathrm{cmd} / \mathrm{cmd}$ (cartilage matrix deficient) mouse. J Biol Chem 256:6961-6968

25. Orkin RW, Pratt RM, Martin GM 1976 Undersulfated chondroitin sulfate in the cartilage matrix of brachymorphic mice. Dev Biol 50:82-94

26. Bingel SA, Sande RD, Wight TN 1985 Chondrodysplasia in the alaskan malamut. Characterization of proteoglycans dissociatively extracted from dwarf growth plates. Lab Invest 53:479-484

27. Nevo Z, Michaeli D, Daentl DL 1978 Examination of core protein of proteoglycans. 1. Abnormal proteoglycan in auriculoepiphyseal dysplasia. Exp Mol Pathol 28:247-255

28. Mourao PAS, Kato S, Donnelly PV 1981 Spondyloepiphyseal dysplasia, chondroitin sulfate type: a possible defect in PAPS-chondroitin sulfate sulfotransferase in humans. Biochem Biophys Res Commun 98:388-396

29. Stanescu V, Stanescu R, Maroteaux P 1984 Pathogenic mechanisms in osteochondrodysplasias. J Bone Joint Surg 66A:817-836

30. Pedrinimille A, Maynard JA, Pedrini VA 1984 Pseudoachondroplasia-biochemical and histochemical studies of cartilage. J Bone Joint Surg 66A:14081414

31. Munsick RA 1984 Human fetal extremity lengths in the interval from 9 to 21 menstrual weeks of pregnancy. Am J Obstet Gynecol 149:883-887

32. Bitter T, Muir H 1962 A modified uronic acid-carbazole reaction. Anal Biochem 4:320-334

33. Jourdian GE, Dean L, Roseman SL 1971 The sialic acids. XI. A periodateresorcinol method for the quantitative estimation of free sialic acids and their glycosides. J Biol Chem 246:430-435

34. Paquin JD, Van der Rest M, Marie PJ, Mort JS, Pidoux I, Poole AR, Roughley PJ 1983 Biochemical and morphologic studies of cartilage from the adult human sacroiliac joint. Arthritis Rheum 26:887-895

35. Santer V, White RJ, Roughley PJ 1981 Proteoglycans from normal and degenerate cartilage of the adult human tibial plateau. Arthritis Rheum 24:691-700

36. Lee GJ, Tieckelmann H 1979 High performance liquid chromatography determination of disaccharides resulting from enzymic degradation of isomeric chondroitin sulfates. Anal Biochem 94:231-236

37. Hjerpe A, Antonopoulos CA, Engfeldt B 1979 Determination of sulphated disaccharides from chondroitin sulphates by high performance liquid chromatography. J Chromatogr 171:339-344

38. Roughley PJ, White RJ, Poole AR 1985 Identification of a hyaluronic acidbinding protein that interferes with the preparation of high-buoyant-density proteoglycan aggregates from adult human articular cartilage. Biochem $\mathrm{J}$ 231:129-138

39. McDevitt CA, Muir H 1971 Gel electrophoresis of proteoglycans and glycosaminoglycans on large-pore composite polyacrylamide-agarose gels. Anal Biochem 44:612-622

40. King J, Laemmli UK 1971 Polypeptides of the tail fibres of bacteriophage T4. J Mol Biol 62:465-477

41. Fairbanks G, Steck TL, Wallach DFH 1971 Electrophoretic analysis of the major polypeptides of the human erythrocyte membrane. Biochemistry 10:2606-2617

42. Towbin M, Staehelin T, Gordon J 1979 Electrophoretic transfer of proteins from polyacrylamide gels to nitrocellulose sheets: procedure and some applications. Proc Natl Acad Sci USA 79:4350-4354

43. Greenwood FC, Hunter WH, Glover JS 1963 The preparation of ${ }^{131}$ I-labelled human growth hormone of high specific activity. Biochem J 89:114-123

44. Campbell IK, Roughley PJ, Mort JS 1986 The action of human articular cartilage metalloproteinase on proteoglycan and link protein. Similarities between in situ and in vitro degradation products. Biochem J 237:117-122

45. Glant TT, Mikecz K, Poole AR 1986 Monoclonal antibodies to different protein-related epitopes of human articular cartilage proteoglycans. Biochem J 234:31-41

46. Roughley PJ, Poole AR, Mort JS 1982 The heterogeneity of link proteins isolated from human articular cartilage proteoglycan aggregate. J Biol Chem 257:11908-11914

47. Mort JS, Caterson B, Poole AR, Roughley PJ 1985 The origin of human cartilage proteoglycan link-protein heterogeneity and fragmentation during ageing. Biochem J 232:805-812

48. Hascall VC 1977 Interaction of cartilage proteoglycans with hyaluronic acid. J Supramol Struct 7:101-120 